\title{
Changes in annual tuberculosis notification rates between 1978/79 and 1983 for the population of Indian subcontinent ethnic origin resident in England
}

\author{
A J NUNN, JANET H DARBYSHIRE, WALLACE FOX, DEBORAHA \\ JOH NSON, AND VH SPRINGETT \\ From the MRC Tuberculosis and Chest Diseases Unit, Brompton Hospital, Fulham Road, London SW3 $6 H P$
}

SUMMARY In two national surveys of tuberculosis notifications in England conducted in 1978/79 and 1983 the estimated annual notification rates for the Indian subcontinent (Indian, Pakistani, and Bangladeshi) ethnic groups were considerably higher than the rate for the white ethnic group. The mean annual decline in rates between the surveys appeared to be greater for the Indian and the Pakistani and Bangladeshi ethnic groups, $15 \%$ and $16 \%$ respectively, than for the white ethnic group (7\%). Data from two small sample population surveys, the National Dwelling and Housing Survey in 1978 and the Labour Force Survey in 1983, were used to calculate the rates. However, comparison of the estimates for the population of Indian subcontinent ethnic origin in England from these surveys revealed discrepancies between them. Additional information from the Labour Force Survey on the year of first entry to the United Kingdom (UK) permitted the calculation of new estimates for the 1978 population, and based on these estimates the annual notification rates for 1978/79 were 287 per 100000 for the Indian and 286 per 100000 for the Pakistani and Bangladeshi ethnic groups. The rates for 1983 were 178 and 169 respectively, and the mean annual decline between the surveys was $11 \%$ for the Indian and $12 \%$ for the Pakistani and Bangladeshi ethnic groups.

There were important changes in the characteristics of the population of Indian subcontinent ethnic origin in England between 1978 and 1983, and therefore the rates for both surveys have been standardised by the method of direct standardisation to a common reference population. Standardising for year of entry to the UK, place of birth (UK or abroad), age, and sex reduced the mean annual decline in the notification rate to $4 \%$ for the Indian and $9 \%$ for the Pakistani and Bangladeshi ethnic groups. The much greater reduction in the rate of decline in the Indian ethnic group is due to the substantial decline between the surveys in the proportion of recent immigrants, the group with the highest annual notification rate, in that population. Future trends will continue to be influenced by immigration patterns, but it will also be important to monitor the rates among the increasing proportion of the population born in the UK or resident in England for more than five years.

Annual tuberculosis notification rates for England and Wales estimated from the 1978/79 and 1983 Medical Research Council (MRC) notification surveys have demonstrated major differences between the white ethnic group and the Indian subcontinent (Indian, Pakistani and Bangladeshi) ethnic groups. ${ }^{12}$ In 1978/79 the notification rates for the Indian and for the Pakistani and Bangladeshi ethnic groups were estimated to be 38 times higher than the rate for the white ethnic group. By 1983 the notification rates in all three groups had declined, with a mean annual decline of $7 \%$ for the white, $15 \%$ for the Indian, and $16 \%$ for the Pakistani and Bangladeshi ethnic groups. Thus the rates for the two Indian subcontinent ethnic groups appeared to be declining much more rapidly than the rate for the white ethnic group. Further analyses have been undertaken to explore this difference in the light of additional population data on the Indian 
subcontinent ethnic groups; the findings are reported here.

\section{Method}

Details of the survey methods have already been reported. ${ }^{12}$ In summary, during the six-month survey periods (1 October 1978 to 31 March 1979 and 1 January to 30 June 1983) the MRC Tuberculosis and Chest Diseases Unit was sent a photocopy of every tuberculosis notification form received by the Medical Officer for Environmental Health for each of the 403 local authorities in England and Wales. In addition, a specially designed patient form, including details of age, sex, ethnic origin, and country of birth, was completed by the clinician in charge for each notified patient. Checks were made which confirmed that copies of all the notifications included in the local authority returns to the Office of Population Censuses and Surveys (OPCS) had been received. A patient form was returned for over $99 \%$ of the patients in the analysis population of both surveys.

\section{CALCULATION OF NOTIFICATION RATES}

\section{Population estimates}

The National Dwelling and Housing Survey (NDHS) of England in $1978^{3}$ and the Labour Force Survey (LFS) of England and Wales in 1983 (OPCS, unpublished data) were $0.5 \%$ stratified random sample surveys from which grossed up population estimates of each of the main ethnic groups were obtained. In order to make comparisons between the two notification surveys the data for England only have been used.

The mid-points of the population surveys were January 1978 and April 1983 respectively and those of the notification surveys 31 December 1978 and 31 March 1983. Thus the midpoint of the NDHS survey was almost 12 months before the corresponding notification survey whereas the LFS and 1983 notification survey coincided closely.

The classification of ethnic origin in the LFS and the two notification surveys was identical and closely similar to that used in the NDHS. Individuals were classified as being of white, Indian, Pakistani, Bangladeshi, West Indian, African, Arab, Chinese, other (including mixed) or unknown ethnic origin. Those in the population surveys for whom the ethnic origin was not obtained (less than $2 \%$ in both surveys) have been distributed proportionately among those for whom the ethnic origin was known.

\section{Notified cases}

As indicated above, the two notification surveys were not conducted at the same time of year, and because there are seasonal differences in the number of notifications reported to the OPCS, the annual number of cases has been estimated by multiplying the number of notified cases for each of the two six-month survey periods by an appropriate scaling factor $(2 \cdot 115$ for $1978 / 79$ and 1.953 for 1983 ).

\section{Results}

The total number of newly notified, previously untreated patients with tuberculosis was 3732 in the $1978 / 79$ survey and 3002 in the 1983 survey (table 1 ). There was a decline both in the number of patients and the estimated annual notification rate in the white, the Indian, and the Pakistani and Bangladeshi ethnic groups. Although there was no decline in rate in the West Indian ethnic group, it is likely that the size of the West Indian population in the 1983 LFS was underestimated (OPCS, personal communication)e and that there was in fact a decline in rate in this group as well. The mean annual decline in the Indian $\stackrel{+}{+}$ subcontinent ethnic groups $(15 \%$ for the Indian and 0 $16 \%$ for the Pakistani and Bangladeshi groups) was

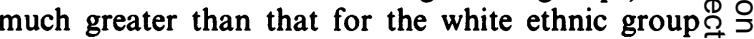
(7\%). This finding was unexpected and has been $\mathbb{\Omega}-\overrightarrow{ }$ explored further using additional data from the 1983유 LFS survey on the structure of the population of the Indian subcontinent ethnic groups in England.

COMPARISON OF I 978 NDHS POPULATION ESTIMATE WITH I 983 LFS ESTIMATE (figure) The estimate of the size of the population of Indian subcontinent ethnic origin in England for 1978 was 829000 (NDHS) and for 1983 was 1220000 (LFS), an

Table 1 Numbers of patients notified, estimated annual notification rates, and mean annual decline in rates between the surveys for the main ethnic groups in England

\begin{tabular}{|c|c|c|c|c|c|}
\hline \multirow[b]{2}{*}{$\begin{array}{l}\text { Ethnic } \\
\text { group }\end{array}$} & \multicolumn{2}{|c|}{$1978 / 1979$} & \multicolumn{2}{|l|}{1983} & \multirow{2}{*}{$\begin{array}{l}\text { Mean } \\
\text { annual } \\
\text { decline in } \\
\text { rate }(\%)\end{array}$} \\
\hline & $\begin{array}{l}\text { Patients } \\
\text { notified } \\
(6 \mathrm{mth})\end{array}$ & $\begin{array}{l}\text { Annual } \\
\text { rate per } \\
100000^{*}\end{array}$ & $\begin{array}{l}\text { Patients } \\
\text { notified } \\
(6 \mathrm{mth})\end{array}$ & $\begin{array}{l}\text { Annual } \\
\text { rate per } \\
100000 t\end{array}$ & \\
\hline White & 2125 & $9 \cdot 4$ & 1668 & 6.9 & 7 \\
\hline Indian & 897 & 354 & 720 & 178 & 15 \\
\hline $\begin{array}{l}\text { Pakistani/ } \\
\text { Bangladeshi }\end{array}$ & 426 & 353 & 377 & 169 & 16 \\
\hline West Indian & 76 & 30 & 79 & 30 & 0 \\
\hline Other & 208 & 97 & 158 & 47 & 16 \\
\hline All groups & 3732 & 16.4 & 3002 & $12 \cdot 2$ & 7 \\
\hline
\end{tabular}

- Based on 1978 NDHS population estimate ${ }^{3}$

+ Based on 1983 LFS population estimate 
Changes in annual tuberculosis notification rates for population of Indian ethnic origin resident in England 359
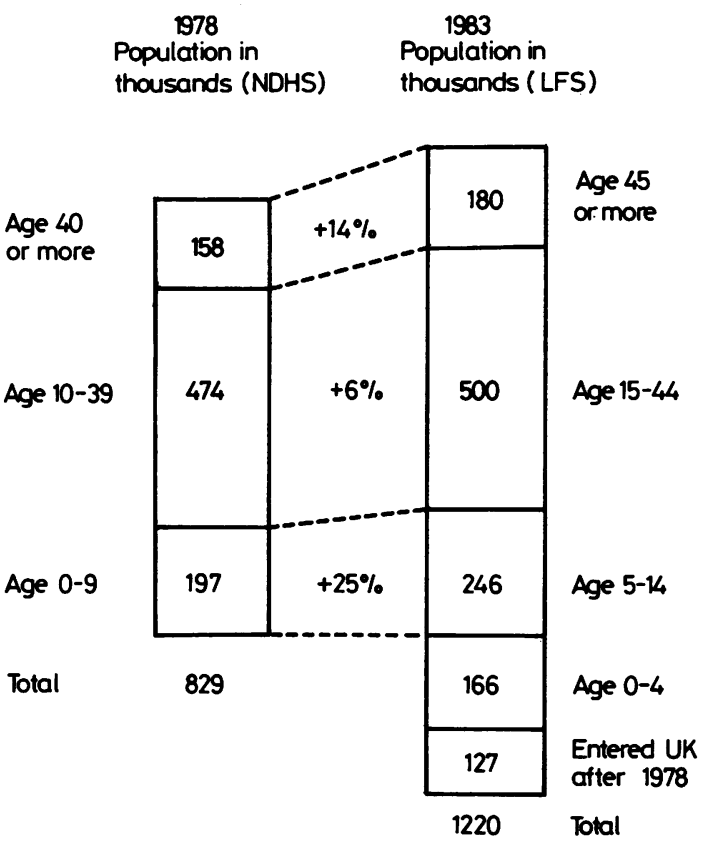

Estimates of size of population of Indian subcontinent ethnic origin resident in England in 1978 and 1983.

apparent increase of $47 \%$. The 1983 estimate included 166000 children born in the previous five years and a further 127000 individuals who first entered the UK in the same period. There were therefore 293000 individuals in the 1983 population who could not have been included in the 1978 estimate. However, if these are subtracted from the 1983 estimate, there remain 927000 individuals who were reported to have been resident in England in April 1978, which is 98000 $(12 \%)$ more than the NDHS estimate for the same population three months earlier. In fact the estimate for the 1978 population based on the 1983 figures should be less, not more, than the 1978 estimate because of the occurrence of deaths and emigration out of the UK. The discrepancy occurs in each of the three age cohorts shown in the figure and is largest $(25 \%)$ for the youngest cohort. The findings are similar in both ethnic groups, the estimates of the number of individuals who were reported to be resident in England in 1978 on the basis of the 1983 data being $13 \%$ more for the Indian group and $9 \%$ more for the Pakistani and Bangladeshi ethnic group. Clearly, these discrepancies will result in either an overestimate of the 1978 notification rate or an underestimate of the 1983 rate, or both.

In order to make a more valid comparison of the rates in the two surveys, estimates for the 1978 population have been made using the 1983 data, that is, it was assumed that the population in 1978 consisted of the 927000 individuals reported in 1983 to have been resident in England in 1978. It was also assumed that the number of individuals dying or leaving the UK between the surveys was a very small proportion of the total and could therefore be ignored. The assumption that the number of deaths would have been small is reasonable in view of the age distribution of the Indian subcontinent ethnic group; only $6 \%$ of the estimated 1983 population were aged 55 years or more. Further support for this assumption comes from the annual death registrations for England and Wales by birthplace of the deceased. In 1982 only 3903 deaths in England and Wales occurred in individuals born in the Indian subcontinent. ${ }^{4}$

As the midpoint of the LFS was April 1983, the new population estimates for 1978 are for April 1978, approximately nine months before the midpoint of the 1978/79 survey (31 December 1978). It therefore has been assumed that $15 \%$ of the increase in the population of Indian subcontinent ethnic origin which occurred between April 1978 and April 1983 had occurred by the end of 1978 . Thus the estimates applicable to the midpoint of the $1978 / 79$ survey are 658000 for the Indian ethnic group and 312000 for the Pakistani and Bangladeshi ethnic group. Increasing the population estimates results in a corresponding decrease in the estimated annual notification rates for $1978 / 79$ from 354 to 287 per 100000 for the Indian ethnic group and from 353 to 286 per 100000 for the Pakistani and Bangladeshi ethnic group. The mean annual decline in rates is reduced by $4 \%$ for both ethnic groups to $11 \%$ and $12 \%$ respectively (line (a) of table 5 ).

The new population estimates for 1978 have been used in all the analyses that follow to calculate the rates for 1978/79.

\section{Notification rates by age and sex}

Revised annual notification rates for $1978 / 79$ for the Indian and the Pakistani and Bangladeshi ethnic groups by age and sex are given in table 2 . In both $1978 / 79$ and 1983 the highest rates for both males and females occurred in the oldest individuals, aged 55 years or more, and the rates were higher for females than for males in most of the age groups. Between the surveys the notification rates declined for all the age groups in both sexes, the mean annual rate of decline ranging from $7 \%$ to $17 \%$.

Notification rates by place of birth and year of first entry to the UK

Both in 1978/79 and in 1983 the highest notification rates occurred in recent immigrants to the UK (table 3). For example, in 1983 the estimated annual notification rate for individuals of Indian ethnic origin entering the UK in the five years immediately before 
Table 2 Estimated annual notification rates by sex and age for Indian and for Pakistani and Bangladeshi ethnic groups in $1978 / 79$ and 1983 based on 1983 population data

\begin{tabular}{|c|c|c|c|c|c|c|}
\hline \multirow{3}{*}{$\begin{array}{l}\text { Sex and age } \\
\text { (yrs) }\end{array}$} & \multicolumn{3}{|l|}{ Indian } & \multicolumn{3}{|c|}{ Pakistani and Bangladeshi } \\
\hline & \multicolumn{2}{|c|}{$\begin{array}{l}\text { Annual notification } \\
\text { rate per } 100000\end{array}$} & \multirow{2}{*}{$\begin{array}{l}\text { Mean } \\
\text { annual } \\
\text { decline in } \\
\text { rate }(\%)\end{array}$} & \multicolumn{2}{|c|}{$\begin{array}{l}\text { Annual notification } \\
\text { rate per } 100000\end{array}$} & \multirow{2}{*}{$\begin{array}{l}\text { Mean } \\
\text { annual } \\
\text { decline in } \\
\text { rate }(\%)\end{array}$} \\
\hline & $1978 / 79^{*}$ & $1983+$ & & $1978 / 79^{*}$ & $1983 t$ & \\
\hline \multicolumn{7}{|l|}{ Male: } \\
\hline $\begin{array}{l}\text { less than } 15 \\
15-34 \\
35-54 \\
55 \text { or more }\end{array}$ & $\begin{array}{r}65 \\
301 \\
276 \\
576\end{array}$ & $\begin{array}{r}34 \\
189 \\
175 \\
339\end{array}$ & $\begin{array}{l}14 \\
10 \\
10 \\
12\end{array}$ & $\begin{array}{c}90 \\
361 \\
347 \\
(471)\end{array}$ & $\begin{array}{r}64 \\
189 \\
256 \\
321\end{array}$ & $\begin{array}{r}8 \\
14 \\
7 \\
9\end{array}$ \\
\hline $\begin{array}{l}\text { Female: } \\
\text { less than } 15 \\
15-34 \\
35-54 \\
55 \text { or more }\end{array}$ & $\begin{array}{r}83 \\
418 \\
466 \\
908\end{array}$ & $\begin{array}{r}49 \\
290 \\
235 \\
405\end{array}$ & $\begin{array}{r}12 \\
8 \\
15 \\
17\end{array}$ & $\begin{array}{r}94 \\
604 \\
449 \\
(1112)\end{array}$ & $\begin{array}{c}55 \\
301 \\
236 \\
(788)\end{array}$ & $\begin{array}{r}12 \\
15 \\
14 \\
8\end{array}$ \\
\hline
\end{tabular}

Rates in parentheses are based on a population of less than 10000 .

* Based on data derived from 1983 LFS

† Based on 1983 LFS population estimate

the survey was 801 per 100000 compared with 236 per 100000 for those entering during the five years before this and 154 per 100000 for those entering more than 10 years before. The occurrence of higher rates in recent immigrants was seen in both ethnic groups and within both surveys, although for the Pakistani and Bangladeshi group there was no trend with duration of stay among those entering the UK more than five years before the survey.

The much lower notification rates for individuals born in the UK are due in part to the fact that the majority (over $85 \%$ ) of them were under the age of 15 years. The rates for children born in the UK were lower than the rates for the children born abroad. Thus, for example, in 1983 the rate for children of Indian ethnic origin born in the UK was 29 per 100000 and for those born abroad 70 per 100000 , the corresponding rates for children of Pakistani and Bangladeshi ethnic origin being 50 and 65 respectively (data not tabulated here, report in preparation).

There were considerable differences in the mean annual decline in rates between the surveys, both between and within the two ethnic groups. Notification rates for individuals of Indian ethnic origin who entered the UK in the five years before the survey increased by an average of $4 \%$ per annum whereas those for the corresponding Pakistani and Bangladeshi group decreased by an average of $14 \%$ per annum. The apparently anomalous finding that the mean annual decline for the entire Indian ethnic group was more than that for the subgroup with the highest rate of decline (namely, those first entering the UK more than 10 years before the survey) is a consequence of the changes in the relative sizes of the subgroups, in particular the decreasing proportion of the population who are recent immigrants.

Effect of changes in population characteristics on the annual notification rates

In a stable resident population, such as the whiteo ethnic group in England, changes in the characteristics $\stackrel{\mathbb{Q}}{\mathrm{Q}}$ 음 of the population within a five-year period are likely to $\underset{\mathbb{Q}}{-}-$ be small and will therefore have little or no effect on $\sigma$ the tuberculosis notification rate. However, the population of Indian subcontinent ethnic origin is $\frac{\mathbb{O}}{3}$ much smaller and is undergoing continual change $\triangle$ because of changes in the pattern of immigration to the UK from the Indian subcontinent and elsewhere." Changes in the characteristics of the population which are known to influence the rates in this ethnic group have therefore been investigated. The importance of the country of birth (UK or abroad) and the number of years since first entry to the UK have already been demonstrated. As immigration declines and the

Table 3 Estimated annual notification rates by birthplace and years since first entry to UK for Indian and for Pakistani and Bangladeshi ethnic groups in 1978/79 and 1983 based on 1983 population data

\begin{tabular}{|c|c|c|c|c|c|c|}
\hline \multirow{3}{*}{$\begin{array}{l}\text { Place of birth and } \\
\text { year of entry to UK }\end{array}$} & \multicolumn{3}{|l|}{ Indian } & \multicolumn{3}{|c|}{ Pakistani and Bangladeshi } \\
\hline & \multicolumn{2}{|c|}{$\begin{array}{l}\text { Annual notification } \\
\text { rate per } 100000\end{array}$} & \multirow{2}{*}{$\begin{array}{l}\text { Mean } \\
\text { annual } \\
\text { decline in } \\
\text { rate }(\%)\end{array}$} & \multicolumn{2}{|c|}{$\begin{array}{l}\text { Annual notification } \\
\text { rate per } 100000\end{array}$} & \multirow{2}{*}{$\begin{array}{l}\text { Mean } \\
\text { annual } \\
\text { decline in } \\
\text { rate }(\%)\end{array}$} \\
\hline & $1978 / 79^{*}$ & $1983 t$ & & $1978 / 79^{*}$ & $1983+$ & \\
\hline \multicolumn{7}{|c|}{ Born abroad and first entered UK: } \\
\hline in previous 5 yr & 674 & 801 & +4 & 659 & 344 & 14 \\
\hline 6-10 yr before & 342 & 236 & 8 & 253 & 218 & 3 \\
\hline$>10$ yr before & 231 & 154 & 9 & 300 & 193 & 10 \\
\hline Born in UK & 59 & 45 & 6 & 71 & 57 & 5 \\
\hline Total population & 287 & 178 & 11 & 286 & 169 & 12 \\
\hline
\end{tabular}

* Based on data derived from 1983 LFS

t Based on 1983 LFS population estimate

+ Indicates an increase in rate 
Table 4 Characteristics of populations of Indian and of Pakistani and Bangladeshi ethnic origin in England in 1978 and 1983

\begin{tabular}{|c|c|c|c|c|c|c|c|c|}
\hline & \multicolumn{4}{|l|}{ Indian } & \multicolumn{4}{|c|}{ Pakistani and Bangladeshi } \\
\hline & \multicolumn{2}{|l|}{$1978^{*}$} & \multicolumn{2}{|l|}{$1983+$} & \multicolumn{2}{|l|}{$1978^{*}$} & \multicolumn{2}{|l|}{$1983+$} \\
\hline & $\begin{array}{l}\text { No. } \\
\text { (thousands) }\end{array}$ & $\%$ & $\begin{array}{l}\text { No. } \\
\text { (thousands) }\end{array}$ & $\%$ & $\begin{array}{l}\text { No. } \\
\text { (thousands) }\end{array}$ & $\%$ & $\begin{array}{l}\text { No. } \\
\text { (thousands) }\end{array}$ & $\%$ \\
\hline $\begin{array}{l}\text { Male } \\
\text { Female }\end{array}$ & 350 & 53 & 411 & 52 & 177 & 57 & $\begin{array}{l}229 \\
202\end{array}$ & $\begin{array}{l}53 \\
47\end{array}$ \\
\hline Female & 308 & 47 & 378 & 48 & 135 & 43 & & \\
\hline $\begin{array}{l}\text { Age }(y r): \\
\text { less than } 15 \\
15-34 \\
35-54 \\
55 \text { or more }\end{array}$ & $\begin{array}{r}211 \\
266 \\
144 \\
37\end{array}$ & $\begin{array}{r}32 \\
40 \\
22 \\
6\end{array}$ & $\begin{array}{r}250 \\
302 \\
175 \\
61\end{array}$ & $\begin{array}{r}32 \\
38 \\
22 \\
8\end{array}$ & $\begin{array}{r}138 \\
97 \\
69 \\
7\end{array}$ & $\begin{array}{r}44 \\
31 \\
22 \\
2\end{array}$ & $\begin{array}{r}195 \\
137 \\
83 \\
15\end{array}$ & $\begin{array}{r}45 \\
32 \\
19 \\
3\end{array}$ \\
\hline Born in UK & 185 & 28 & 266 & 34 & 104 & 33 & 164 & 38 \\
\hline $\begin{array}{l}\text { Born abroad: } \\
\text { entered in previous } 5 \mathrm{yr} \\
\text { entered } 6-10 \mathrm{yr} \text { before } \\
\text { entered }>10 \mathrm{yr} \text { before }\end{array}$ & $\begin{array}{l}119 \\
143 \\
211\end{array}$ & $\begin{array}{l}18 \\
22 \\
32\end{array}$ & $\begin{array}{r}58 \\
129 \\
335\end{array}$ & $\begin{array}{r}7 \\
16 \\
42\end{array}$ & $\begin{array}{l}61 \\
55 \\
92\end{array}$ & $\begin{array}{l}20 \\
18 \\
29\end{array}$ & $\begin{array}{r}69 \\
60 \\
138\end{array}$ & $\begin{array}{l}16 \\
14 \\
32\end{array}$ \\
\hline Total population & 658 & 100 & 789 & 100 & 312 & 100 & 431 & 100 \\
\hline
\end{tabular}

* Based on data derived from 1983 LFS

† Based on 1983 LFS population estimate

proportion of children of Indian subcontinent ethnic origin born in the UK increases, so the proportion of the Indian subcontinent population with the highest notification rates, that is, those born abroad who have most recently arrived in the UK, will also decline.

Between 1978 and 1983 there was little change in the sex or age distribution of the Indian and the Pakistani and Bangladeshi ethnic groups in England (table 4). The most important change was in the proportion of recent immigrants in the population. In $1978,18 \%$ of the Indian and $20 \%$ of the Pakistani and Bangladeshi ethnic groups had entered the UK in the previous five years whereas in 1983 the corresponding proportions were $7 \%$ and $16 \%$ respectively. Over the same period the proportion of the population born in the UK had increased in both ethnic groups. The effect of these latter two changes would be a decrease in the notification rate.

\section{Direct standardisation of notification rates}

In order to allow for the changes in relevant population characteristics when comparing the notification rates in 1978/79 and 1983, the rates have been standardised by the direct method using the mean of the revised 1978 and the 1983 estimates as the reference population. Standardisation was initially performed for place of birth and years since first entry to the UK. The analysis was repeated standardising also for age and sex. The mean annual declines in rates between the surveys following standardisation are given for the Indian and the Pakistani and
Table 5 Mean annual decline in notification rate for Indian subcontinent ethnic groups after revision of 1978 population estimate and after direct standardisation for birthplace, years since first entry to $U K$, age, and sex

\begin{tabular}{|c|c|c|c|}
\hline & \multicolumn{3}{|c|}{ Mean annual decline in rates $\%$} \\
\hline & Indian & $\begin{array}{l}\text { Pakistani \& } \\
\text { Bangladeshi }\end{array}$ & $\begin{array}{l}\text { Both groups } \\
\text { combined }\end{array}$ \\
\hline Using 1978 NDHS population estimate & 15 & 16 & 15 \\
\hline \multicolumn{4}{|l|}{ After deriving 1978 estimate from 1983 LFS } \\
\hline $\begin{array}{l}\text { (a) with out standardisation } \\
\text { (b) with standardisation for birthplace }\end{array}$ & 11 & 12 & 11 \\
\hline $\begin{array}{l}\text { and years since first entry to UK } \\
\text { with standardisation for age, sex, } \\
\text { birthplace and years since first entry } \\
\text { to UK }\end{array}$ & $\begin{array}{l}3 \\
4\end{array}$ & 10 & 7 \\
\hline
\end{tabular}

Bangladeshi ethnic groups separately and for the combined Indian subcontinent ethnic group (table 5).

After revision of the population estimates for 1978, the mean annual decline was $11 \%$ for the Indian and $12 \%$ for the Pakistani and Bangladeshi ethnic groups. After allowing for standardisation for differences in birthplace and years since first entry to the UK, the annual rate of decline was estimated to be $3 \%$ for the Indian and $10 \%$ for the Pakistani and Bangladeshi ethnic groups. The differences in immigration patterns between 1978 and 1983 have had a greater influence on the rates in the Indian than in the Pakistani and Bangladeshi ethnic groups. The considerable 
reduction before standardisation in the notification rate in the Indian ethnic group between 1978 and 1983 was largely due to the marked reduction in the proportion of recent immigrants.

The effect of changes in the age and sex distributions between the populations were relatively unimportant. After allowing for these also, the annual rates of decline were found to be $4 \%$ for the Indian and $9 \%$ for the Pakistani and Bangladeshi ethnic groups. These are likely to be the best estimates of the mean annual declines in notification rates between the two surveys.

\section{Discussion}

Surveys conducted by the Medical Research Council and the British Thoracic Association have shown that, apart from the white ethnic group, the two ethnic groups contributing the largest number of tuberculosis notifications in England and Wales are the Indian and the Pakistani and Bangladeshi ethnic groups. In 1965 and 1971, population estimates for these ethnic groups were based on country of birth. ${ }^{56}$ Population estimates for 1983 derived from the LFS indicate that over one third of the population of Indian subcontinent ethnic origin in England in that year had been born in the UK. In addition, a substantial number of individuals of Indian subcontinent ethnic origin living in England had been born in East Africa. Thus the birthplace of the individual can no longer be relied upon for population estimates, nor is it possible to estimate these populations accurately from data based on the birthplace of the head of the household. In order to obtain the relevant population estimates it has become necessary to ascertain the ethnic origin of each individual directly. It was intended to collect this information in the 1981 census of England and Wales, but a question on ethnic origin was not included because of difficulties encountered in pilot surveys.

The only population data on ethnic origin come from small sample population surveys such as the NDHS and the LFS. The procedure adopted at each of these surveys was to ask an adult member of each household sampled (usually the head or spouse of head of household) to indicate from a list of ethnic origins which most closely described each member of his or her household. Although this method may be a satisfactory way of obtaining estimates for the majority population of white ethnic origin, there are serious disadvantages when it is used to estimate the size of other ethnic groups. In the 1983 LFS the ethnic origin was not determined for almost $2 \%$ of those sampled, more than the total number described as being of Indian ethnic origin. Analysis of the available information from the 1983 LFS on birthplace, parents' birthplace, and head of household's ethnic group has shown that the vast majority of such persons are likely to be white. ${ }^{7}$ The $2 \%$ have therefore been distributed proportionately among the groups for whom the ethnic origin is known.

A more serious problem is the basis of the random sampling frame. Because of the clustering of immigrants in certain local authority areas and in certain streets within these areas, population estimates are dependent not only on the size of the sample but more importantly on the areas selected. The discrepancies between the 1978 NDHS and 1983 LFS population estimates of the size of the Indian subcontinent population resident in England in 1978 are likely to be attributable in particular to the choice of households rather than to individuals as the basis of the random sample. The 1983 data were used to align the two population estimates because they included information on the year of entry of those born abroad, which was not available in the NDHS estimates.

After deriving new population estimates for 1978, the decline in notification rate for the two Indian subcontinent ethnic groups was reduced from $15 \%$ to $11 \%$ per annum. There were however, important changes in the characteristics of the Indian subcontinent ethnic groups in the period between the two surveys. In particular, the proportion of these ethnic groups who are recent immigrants (and known to have the highest notification rates) is declining. After direct standardisation of the rates for place of birth (UK or abroad), years since first entry to the UK, age, and sex, the mean annual decline in rates was $4 \%$ for the Indian and $9 \%$ for the Pakistani and Bangladeshi ethnic groups, much closer to the $7 \%$ annual decline in the white ethnic group. Much of the apparent steep reduction in the rates between the surveys is thus seen to be due to changes in the characteristics of the population of these ethnic groups in the intervening five-year period, especially for the Indian ethnic group. It is of interest also to note that the rate of decline of notification rate in those of Indian and of Pakistani and Bangladeshi ethnic origin who were born in the UK (over $85 \%$ of whom are children) is very close to that of the white population, namely, $6 \%$ and $5 \%$ per annum respectively.

The implications of these findings are important for future tuberculosis control in England and Wales. The total number of patients of Indian subcontinent ethnic origin showed a reassuring decline of $23 \%$ (corrected for seasonal variation) in the $4 \frac{1}{4}$ years between the midpoint of the two notification surveys, and there was a decline in the notification rates. This report has shown that the decline in the crude rates for both the Indian and the Pakistani and Bangladeshi ethnic groups was due in part to changes in the characteristics of those populations. The crude rates are likely to continue to decline as the proportion of recent immigrants among the population of Indian subcontinent ethnic origin also declines. However, this 
report has also shown that, in addition to the effects of the changing population characteristics, there have been inherent declines of $4 \%$ and $9 \%$ annually in the notification rates for these two ethnic groups, and the declines of $6 \%$ and $5 \%$ annually for those in these groups who were born in the UK are closely similar to the annual decline of $7 \%$ for the white population as a whole. These findings suggest that future declines in the crude notification rates for the Indian subcontinent ethnic groups will continue to be greater than in the white population, and will gradually narrow the present large gap between the notification rates in the Indian subcontinent and white ethnic groups.

It is clearly important to monitor changes in the notification rate in these ethnic groups, especially as patterns of immigration change and as the age of population increases (in 1983 only $8 \%$ of the Indian and $3 \%$ of the Pakistani and Bangladeshi ethnic groups were aged 55 years or more). Future trends in notification rates will be influenced by many factors, in particular by immigration patterns, the rates among the increasing numbers born in the UK, and the rates among those already resident here.

We are grateful to all the Medical Officers for Environmental Health, chest physicians, and clinicians in many other specialities who together with their staff made the success of this survey possible. The population data from the National Dwelling and
Housing Survey were provided by the Department of the Environment and those for the Labour Force Survey by the Office of Population Censuses and Surveys. Dr Ian Sutherland gave valuable advice on the presentation of the findings.

\section{References}

${ }^{1}$ Medical Research Council. National survey of tuberculosis notifications in England and Wales 1978/79. Br Med J 1980; 281: 895-8.

${ }^{2}$ Medical Research Council. National survey of tuberculosis notifications in England and Wales in 1983. Br Med J 1985; 291: 658-61.

${ }^{3}$ Department of the Environment. National Dwelling and Housing Survey. London: HMSO, 1979.

${ }^{4}$ Office of Population Censuses and Surveys. Deaths by birthplace of deceased 1982. Monitor DH1 84/1, London: OPCS, 1984.

${ }^{5}$ British Tuberculosis Association. Tuberculosis among immigrants to England and Wales: a national survey in 1965. A report from the Research Committee of the British Tuberculosis Association. Tubercle 1966; 47: $145-56$.

${ }^{6}$ British Thoracic and Tuberculosis Association. A tuberculosis survey in England and Wales 1971; the influence of immigration and country of birth upon notifications. A report from the Research Committee of the British Thoracic and Tuberculosis Association. Tubercle 1973; 54: 249-60.

${ }^{7}$ Office of Population Censuses and Surveys. Labour Force Survey 1984: Country of birth, ethnic group, year of entry and nationality. Monitor LFS 85/1, London: OPCS, 1985. 